Nachruf

\title{
Zum Tod von Dr. Michael Reinhard
}

\begin{abstract}
Die rheinland-pfälzische Zahnärzteschaft trauert um Dr. Michael Reinhard. Er starb im August plötzlich und unerwartet im Alter von 67 Jahren. Reinhard wurde 1947 in Koblenz geboren. Mit seiner Heimatstadt blieb er auch ein Leben lang fest verbunden. Nach erfolgreich absolviertem Mathematik- und Zahnmedizinstudium in Bonn und Marburg ließ er sich 1982 in eigener Praxis in Koblenz nieder.
\end{abstract}

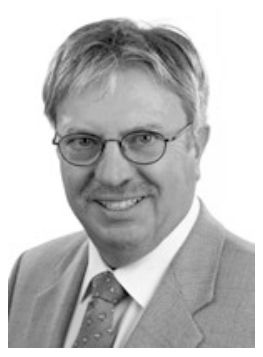

Schnell lernte Michael Reinhard über das Praxisalltagsgeschehen hinauszuschauen und engagierte sich ab 1986 in der Standespolitik. In der damaligen Kassenzahnärztlichen Vereinigung Koblenz-Trier startete er zunächst in den Gremien der Prüfungsausschüsse. Ob seiner fundierten mathematischen Kenntnisse und seines hohen Einsatzes wurde Kollege Reinhard 1990 Mitglied im dortigen KZV-Vorstand und 2002 stellvertretender Vorsitzender. Nach der Fusion der rheinlandpfälzischen KZVen wählte ihn die Vertreterversammlung zunächst in den Vorstand und 2007 zum stellvertretenden Vorsitzenden. Ein Amt, das er bis zu seinem Tod innehatte.

Außerdem arbeitete Reinhard in zahlreichen Ausschüssen der Bezirkszahnärztekammer Koblenz und der Landeszahnärztekammer, in beiden Organisationen zeitweilig auch in den Vorständen. Im Kammerbereich galt seine besondere Leidenschaft der Öffentlichkeitsarbeit, auch organisierte er in den vergange- nen Jahren bestens das Qualitätsmanagement für die rheinlandpfälzischen Praxen.

Dem Freien Verband Deutscher Zahnärzte trat Reinhard 1999 bei. Als Delegierter zur Landesversammlung und gern gesehener Gast der Vorstandssitzungen auf Bezirks- und Landesebene war sein Rat stets gefragt.

Der Absolvent der Akademie für zahnärztliche Selbstverwaltung förderte und begleitete mit seinem großen Wissen auch den standespolitischen Nachwuchs.

Wegen seiner Verdienste um das Wohl der rheinland-pfälzischen Zahnärzteschaft wurden Dr. Michael Reinhard die Verdienstmedaille der Landeszahnärztekammer und die Ehrennadel der Deutschen Zahnärzte verliehen.

Unsere Gedanken und unser Mitgefühl in dieser schweren Stunde des Abschieds sind bei seiner Frau und der Familie. Wir werden ihm ein ehrendes Andenken bewahren.

Für den FVDZ-Landesverband Rheinland-Pfalz

Dr. Marianne Biermeyer, Ehrenvorsitzende

Initiative proDente

\section{Joachim Hoffmann bleibt Vorstandsvorsitzender}

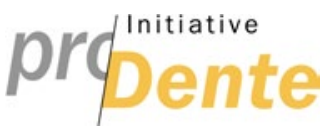

Der Vorstand der Initiative proDente hat Joachim Hoffmann als Vorstandsvorsitzenden des Vereins bestätigt. Hoffmann vertritt den Freien Verband Deutscher Zahnärzte (FVDZ) in der Initiative. Zugleich wählte die Initiative Dr. Markus Heibach (VDDI) und Thomas Lüttke (VDZI) erneut als stellvertretende Vorsitzende. Der Vorstand bestimmte Lutz Müller (BVD) wieder zum Schatzmeister des Vereins. Die Bundeszahnärztekammer (BZÄK) entsendet Prof. Dr. Dietmar Oesterreich in den Vorstand der Initiative proDente.
Im vergangenen Jahr verzeichnete proDente eines der erfolgreichsten Jahre ihres Bestehens. Die mediale Aufmerksamkeit blieb 2014 auf hohem Niveau. Mit einer Reichweite von über 260 Millionen Kontakten erreichte die Medienarbeit des Vereins statistisch jeden Deutschen dreimal im Jahr. Über 370.000 Broschüren versendete proDente im vergangenen Jahr. Besonders stark wuchsen die Besuche auf der Internetseite, die über 450.000 Nutzer besuchten.

Nähere Infos unter www.prodente.de.

\section{An zwei Orten und zwei Terminen}

\section{Deutscher Zahnärztetag in Hamburg und Frankfurt}

Der Deutsche Zahnärztetag läuft diesen Herbst in zwei verschiedenen Städten und an zwei unterschiedlichen Terminen. Der Standespolitische Teil findet vom 28. bis 31. Oktober 2015 in Hamburg statt. Dort stehen sowohl die Vertreterversammlung der Kassenzahnärztlichen Bundesvereinigung (KZBV) als auch die Bundesversammlung der Bundeszahnärztekammer
(BZÄK) auf dem Programm. Der Wissenschaftliche Kongress der Deutschen Gesellschaft für Zahn-, Mund- und Kieferheilkunde (DGZMK) bleibt am bisherigen Standort und ist vom 6. bis 7. November in Frankfurt am Main. Der Deutsche Zahnärztetag ist eine gemeinsame Veranstaltung der BZÄK, der KZBV und der DGZMK. Nähere Infos unter $\boldsymbol{w} w \boldsymbol{w}$.dtzt.de. 